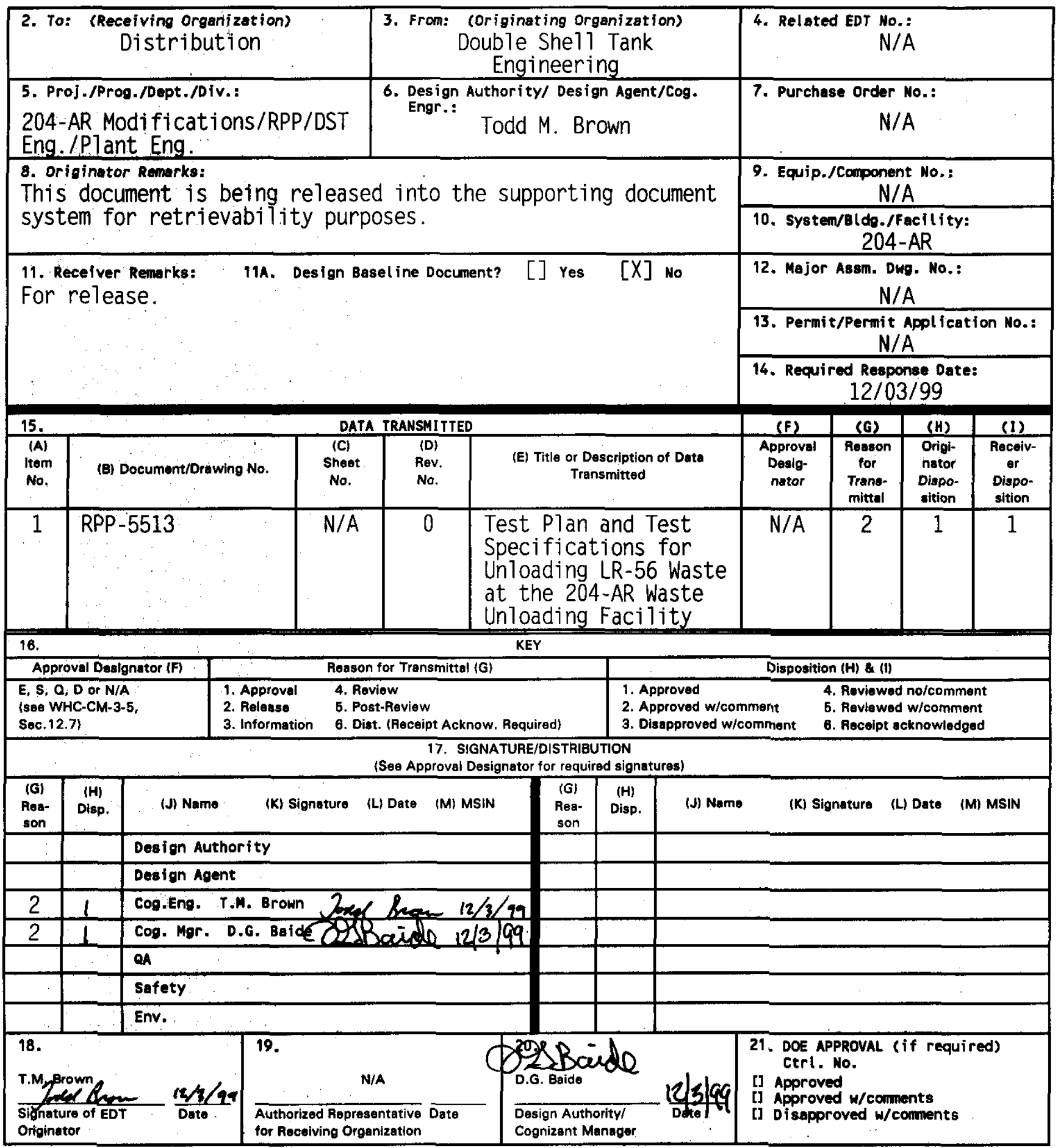

BD-7400-172-2 (05/96) GEF097 
DISTRIBUTION SHEET

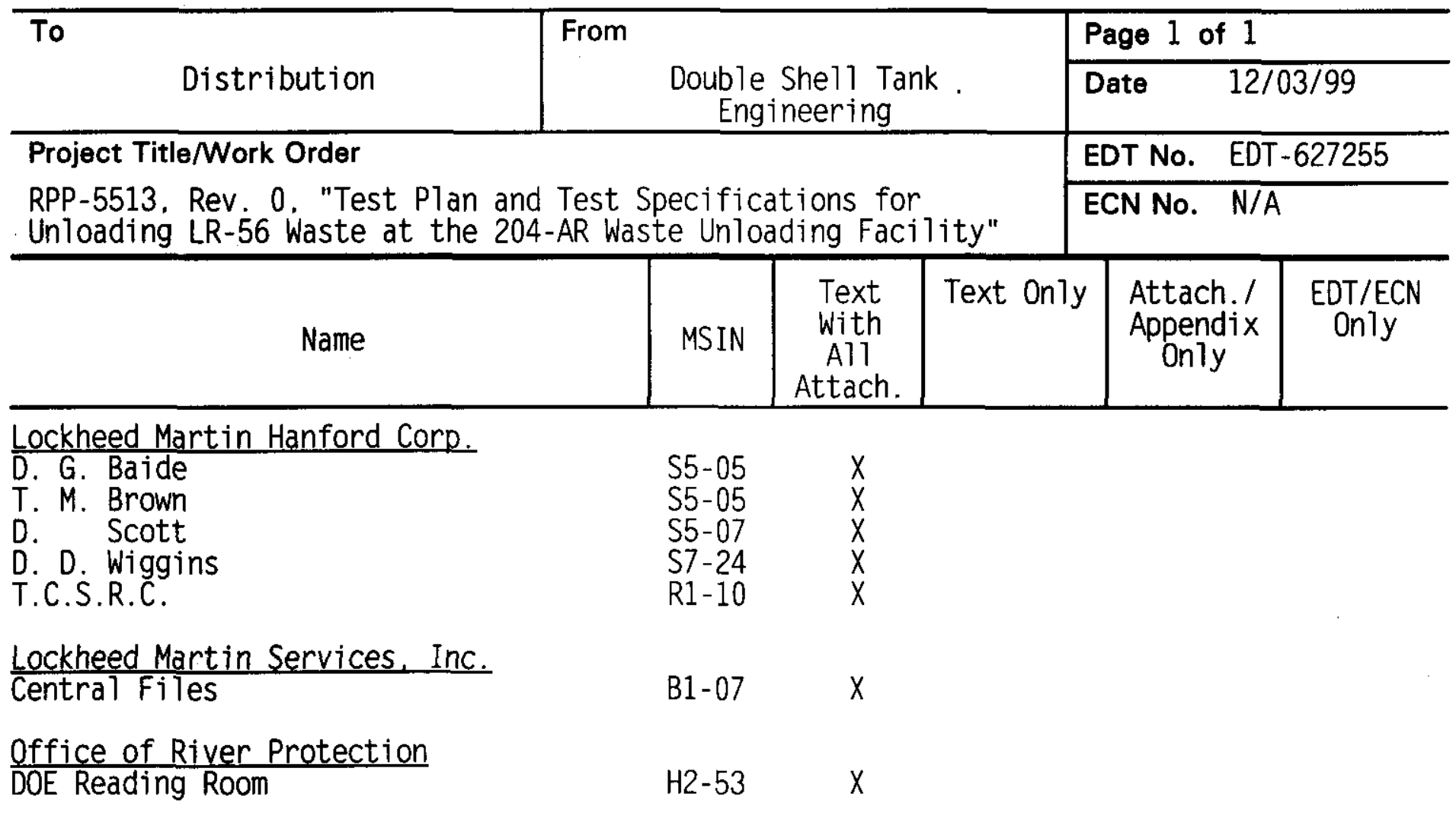


0

\section{Test Plan and Test Specifications for Unloading LR-56 Waste at the 204-AR Waste Unloading Facility}

Todd M. Brown

Lockheed Martin Hanford, Corp., Richland. WA 99352

U.S. Department of Energy Contract DE-AC06-96RL13200

EDT/ECN: EDT-627255

Org Code: 74100

UC: 2070

B\&R Code: EW 3120074 Total Pages: //

Key Words: Test Plan, Test Specifications, LR-56. Waste, 204-AR, Waste Unloading

Abstract: $N / A$

TRADEMARK DISCLAIMER. Reference herein to any specific commercial product, process, or service by trade name, trademark, manufacturer, or otherwise, does not necessarily constitute or imply its endorsement, recommendation, or favoring by the United States Government or any agency thereof or its contractors or subcontractors.

Printed in the United States of America. To obtain copies of this document, contact: Document Control Services, P.O. Box 950, Mailstop H6-08, Richland WA 99352, Phone (509) 372-2420; Fax (509) 376-4989.
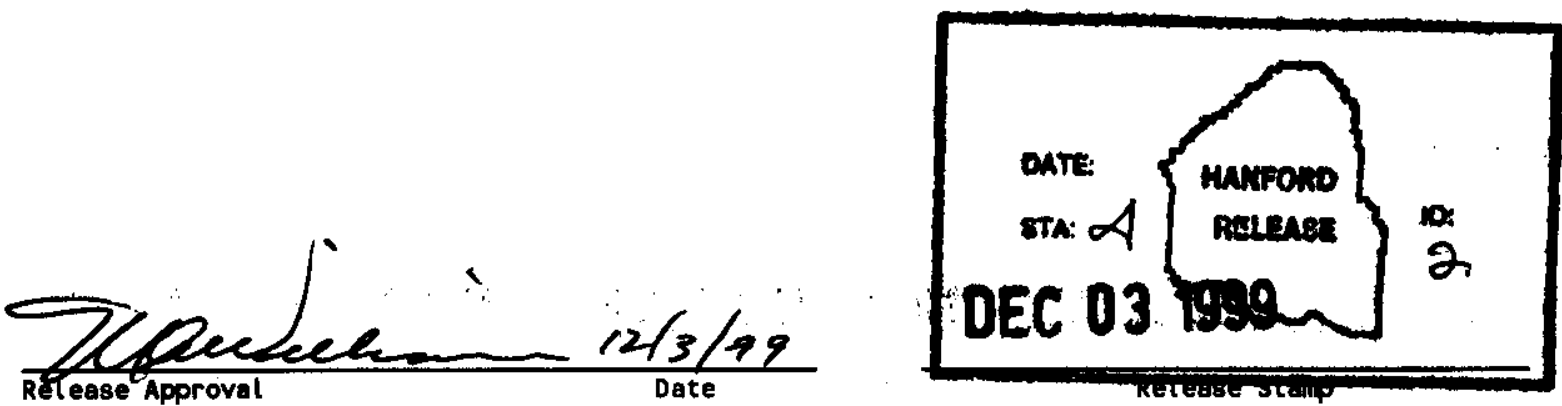

Approved for Public Release 


\section{Test Plan and Test Specifications \\ For Unloading LR-56 Waste at the 204-AR Waste Unloading Facility}

\subsection{PURPOSE}

The LR-56 cask is an International Atomic Energy Agency (IAEA), type B (U) certified Medium to High Level Radioactive Liquid Waste Transport Cask. The LR-56 consists of a trailer equipped with the following component and systems:

- 4 cubic meter lead shielded cask

- Self-contained ventilation system including an air pressure/vacuum pump for cask loading and unloading

- Waste temperature, level, leak detection, and other surveillance equipment

- Control room for control of loading and unloading operations and waste surveillance

- Hoist system for removing well caps on the cask

- Power connection and control connections for operating the cask from a remote facility

The cask may be unloaded or loaded using either the onboard pressure/vacuum pump or by an external waste transfer pump. Rinse heads and connections allow the cask to be rinsed using supplied rinse water. The cask was designed to be vented using the LR-56 onboard ventilation system, which is connected to the cask via a hose through a penetration in the cask. Three wells $(9,10$ and 11$)$, located on the top of the cask, offer valved penetrations into the cask for venting, waste pumping, and rinsing. Other penetrations in the cask enable surveillance instrumentation to be used to monitor inside the cask.

To date, the LR-56 cask system at the Hanford facility has not been used. Since the vessel has never received radioactive waste, the LR-56 is not yet a regulated system. It is desired to use the LR-56 cask to transport waste in calendar year 2000.

Initial use of the LR-56 trailer will be for laboratory waste, which will be loaded into the LR-56 at the Pacific Northwest National Laboratory (PNNL), 325 building, will be unloaded at the 204AR waste unloading facility and pumped into the double-shell tank system. The waste will be pumped out using the 204-AR waste transfer pump P1-B instead of the LR-56 pressure/vacuum pump. The on-board ventilation system will be bypassed and the 204-AR ventilation system will be used in its place. In preparation for receiving the PNNL waste, modifications have been made to the 204-AR waste unloading facility. Modifications to the 204-AR waste unloading facility are summarized below:

- Waste, rinse, and vent jumpers - jumpers were fabricated to connect the LR-56 cask with the hoses at 204-AR. Ventilation of the LR-56 cask will be performed through the 204-AR ventilation system, for which a ventilation jumper was fabricated. Rinsing will be performed in each of the three cask wells, for which a rigid, threehead rinsing jumper was fabricated.

- Rinse head water supply valves - solenoid valves were installed on the rinse jumper to control the supply of rinse water to the three sections of the cask. The solenoid valves may be controlled from the 204-AR control room. 
- Power connection to the LR-56 cask - a 460-Volt, $60 \mathrm{~Hz}$, three phase plus ground line and safety shut-off switch was supplied to the unloading room for the purpose of powering the LR-56 cask system.

- Control connection to the LR-56 cask and 204-AR controls - new controls were wired into the control panel board in the 204-AR control panel room. The changes allow operators to control unloading and rinsing operations at the LR-56 from the control room, instead of from the LR-56 control panel board. Another connection allows operators in the 204-AR control room to monitor the LR-56 cask level. A control cable was installed in the unloading room to connect the LR-56 cask system and the rinse solenoid valves with the 204-AR control panel board.

- Pump P1-B variable speed drive (VSD) - a variable speed drive was connected to the power supply of 204-AR transfer pump P1-B. The variable speed drive was installed to ensure that the waste is pumped out of the cask at a slow enough rate to control the unloading process (P1-B is normally used to pump waste out of $5000 \mathrm{gal}$ tanker trailers, a much larger capacity than the LR-56).

- Pump P1-B and solenoid valve interlocks - interlocks were wired into the pump P1-B and into the rinse control solenoid valves to help control the unloading and rinsing processes. The purpose of the pump interlock is to close out pump P1-B when the LR-56 is not in rinse or unloading mode. The purpose of the solenoid valve interlock is to close the rinse raw water supply when the rinse water level in the LR-56 cask reaches the safe limit.

- Pressure reduction of raw water supply - a pressure-reducing valve was installed on the raw water supply line to help control the final pressure on the LR-56 rinse heads.

Prior to the first transfer of waste through the LR-56, the systems and components listed above must be tested. The purpose of this test plan and test specification document is to plan the desired acceptance testing procedure (ATP) that will be used to validate the modifications made at 204AR. The ATP will also ensure that the systems on the LR-56 perform their desired functions, and that LR-56 systems communicate with 204-AR systems as designed.

\subsection{LR-56 WASTE UNLOADING PROCESS DESCRIPTION}

The unloading process at 204-AR will start after the waste is loaded into the LR-56 cask at the 325 laboratory and delivered to East Tank Farms at the 204-AR building. Waste transfer out of the LR-56 will be performed in parallel with another Tank Farms transfer procedure that assumes responsibility for the waste from the time that it is pumped out of the 204-AR facility until it is received at the receiving double-shell tank. Following is a summarized description of the waste unloading process.

Upon reception of the LR-56 at the 204-AR facility, the facility is set up for unloading. Jumper preparation, valve line-ups, and other preparation work are performed before the LR-56 is brought into the building. To minimize exposure and contact with contamination of the operators, all of the hoist work on the LR-56 is performed while the trailer is parked outside of the 204-AR facility. Operation of the hoist outside of the facility requires that the power cable be brought out of the facility and hooked up with the LR-56. After the power is hooked up, the hoist is used to remove the well covering plugs. After the plugs are removed, and the power disconnected, the trailer is brought into the unloading room in 204-AR and positioned for hook up to the transfer hoses. 
The fabricated jumpers are connected to the vent, rinse, and unloading manually valved penetrations in the three wells and then joined to the hoses to connect the LR-56 with 204-AR piping. Power and controls are re-connected to bring the LR-56 on line and in communication with the control panel board in the 204-AR control room. As soon as the LR-56 is on line, and the control panel board is connected to the LR-56, the waste transfer pump P1-B cannot be operated because of an interlock. Operators will able to read the level of waste in the cask from the control panel board. Even though most transfer operations can be controlled from the 204-AR control panel board, operators will need to use the LR-56 control panel to set the LR-56 into unload and rinse modes. After the LR-56 is set to the unload cycle from the control panel, the remainder of the waste unloading is controlled and monitored from the 204-AR control room.

From the 204-AR control panel board an operator depresses the "request to transfer" button and waits for the LR-56 to send a permissive signal. When the "transfer authorized" light is lit (indicating permission from the LR-56), the transfer is initiated by starting pump P1-B. At this point, the P1-B pump interlock should reset, allowing the pump to start. The rate of pumping is controlled using the variable speed drive, which was just installed. Pumping continues until the waste is unloaded. Stopping pump P1-B terminates the unloading operation. The cask is now ready for the rinsing cycle.

Rinsing cannot be performed until the LR-56 is set to the rinsing cycle, which must be performed by an operator at the LR-56 control panel. After the LR-56 is set to the rinsing cycle, the "start" rinse button is depressed at the 204-AR control panel board and again the system waits until a permissive signal is sent from the truck. When the "rinsing authorized" light is lit (indicating permission from the LR-56), the rinsing may be initiated. The rinse solenoid valves will not open until the "rinsing authorized" signal is sent from the LR-56. Rinsing is performed one section at a time (there are three sections in the LR-56, each one associated with a well). The rinse water pressure is a critical parameter and is controlled by the new raw water supply line pressure reducing valve, by the new variable speed drive and by a diaphragm operated valve on the rinsing line. When the rinse water reaches a volume of 1 cubic meter in the cask, the rinse cycle ends automatically, causing the rinse solenoid valves to close and pump P1-B to shut off. After each section is rinsed, the rinse water is pumped out of the cask using the unloading cycle (described in the previous paragraph). Each time the unloading cycle or the rinsing cycle is initiated, an operator is required to set the cycles at the LR-56 control panel (in the unloading room).

Upon completion of the unloading and rinse cycles, the waste transfer lines are rinsed by pumping water from the catch tank through the waste transfer route to the receiving double shell tank. The manual valves on the cask penetrations are closed and the LR-56 is then disconnected physically from the vent, rinse, and waste transfer hoses. The LR-56 is then electrically disconnected from its power source and from the control cable, which linked it to the 204-AR control panel board. Finally, the LR-56 is pulled outside of the building so that the hoist work of restoring the heavy well caps can be completed.

\subsection{TEST PLAN}

Two phases of testing will be performed on the LR-56/204-AR waste unloading system before the cask is put into operation. The first phase, the ATP, is described in this test plan. The second phase of testing is the operational test procedure (OTP), which will be developed and executed after completion of the ATP. The ATP will be performed with the LR-56 trailer parked outside of the 204-AR facility, but connected electrically (power and controls) to the facility. This will ensure that the LR-56 remains uncontaminated throughout the ATP. The ATP will evaluate 
individual components of the LR-56/204-AR interface, whereas the OTP will evaluate the entire system functioning together. The results of the ATP will be used to develop an operating procedure, which will be tested in the second phase of testing via the OTP. The OTP will actually perform a transfer of water out of the LR-56 (with the cask parked in the facility and physically hooked up). After completion of the OTP, the cask will have been connected to a contaminated waste line and the LR-56 will become a regulated system.

The Sections below will outline the ATP. The order of testing is important as the latter tests require that power to the LR-56 cask is supplied and that the controls interface is connected between the LR-56 cask and the 204-AR panel board. The tests described in Section 3.1 must be performed prior to Sections 3.2 through 3.4. Sections 3.2 and 3.3 may be performed in any order once Section 3.1 is completed. Sections 3.4 may be performed after Sections 3.2 and 3.3 are completed. Section 3.5 is independent of the other Sections and may be performed at any time.

\subsection{Test of Power Connection to the LR-56 Cask}

Preliminary - prior to testing the power connection of the LR-56 cask, cask should be parked outside of 204-AR and leveled. Power cord should be brought outside of the building from the unloading room, and set inside of the railroad tracks to ensure that the door does not pinch the cable. The three signal cables that connect the cask to the LR-56 control panel will need to be connected.

The power cable will be plugged into the LR-56 and the power switch inside the control room of the LR-56 and inside of the unloading room will be closed. After power is connected to the cask, the LR-56 system may be brought on-line by turning switch S1 to "on-line". Power will be verified by control panel lights being lit, and by verification that the LR-56 back up battery is being charged. This Section may be performed in parallel with Section 3.3, by plugging in the control cable prior to powering up the LR-56.

\subsection{Test of Fit of Waste Transfer, Vent, and Rinse Fabricated Jumpers}

Preliminary - the fit of the jumpers may not be tested until the well caps are removed. The hoist may be operated to remove the caps after power is supplied to the LR-56 (Section 3.1 must be completed prior to performing this Section). A personnel lift will be needed in the unloading room to reach to hoses.

The jumpers will be connected to the valves inside each of the 3 wells to ensure that a proper fit is obtained. The jumpers will then be connected to the hoses inside of the unloading room to ensure that a proper fit is obtained. Only one end of the jumper is connected at a time since the LR-56 will remain outside of the building throughout the test. The OTP will test the fit of the jumpers when both ends are connected at once, and will leak test the jumpers during operation.

\subsection{Test of Control Connection to the LR-56, 204-AR Controls and Unloading Cycle Interlocks}

Preliminary - In conjunction with connecting the control cable to the LR-56 and to turning on the 204-AR controls for the LR-56, the power must be turned on to the LR-56 (The power connections made in Section 3.1 must be completed in parallel with this Section). When testing pump P1-B interlocks, the electrical power supply leads to the pump motor should be lifted to ensure that administrative control (AC) 5.20 remains effective. 
Control cables are hooked up to the LR-56 while power cables are being hooked up. After both cables are connected, power switches are opened and the truck is turned on-line. After the truck is turned on-line, the LR-56 "Power" switch on the 204-AR control panel board may be turned "on". Testing of the LR-56 control circuit will verify that the "Power On" and the "LR-56 Connected" lights come on. Testing will be performed to show that under an emergency shutdown condition in the LR-56 truck, the "LR-56 Connected" light turns off. A test of the pump P1-B interlock will also be performed to ensure that while the LR-56 is connected and the "unloading" or "rinse" cycles are not on that pump P1-B may not be activated.

The waste unloading cycle will be tested next. After operators set switches inside the LR-56 control panel to the "External/Indoors Unloading" cycle, the "Request to Transfer" button on the 204-AR control panel board may be depressed, which sends a signal to the LR-56 cask requesting a permissive signal to begin pumping using an external pump. Permission from the LR-56 is given by energizing the "Transfer Authorized" light on the 204-AR control panel board. Testing will verify that pump $\mathrm{P} 1-\mathrm{B}$ is operable while the external/indoors unloading cycle is active.

The rinse cycle will be tested in Section 3.4 .

\subsection{Test of Rinse Water Supply Valves and Rinse Cycle Interlocks}

Preliminary - Rinse water supply valves cannot be tested until the controls are connected between the LR-56 cask and the 204-AR control panel board (Section 3.3 must be completed before performing this Section). Prior to performing testing on the rinse cycle, the cask must contain less than 1 cubic meter of water. To be able to test the end rinse cycle interlocks, water must be filled into the cask while the cask is in rinse cycle (Section 3.2 must be completed before performing this Section so that water may be pumped into the cask through a well head). When testing pump P1-B interlocks, the electrical power supply leads to the pump motor should be lifted to ensure that administrative control (AC) 5.20 remains effective. To test the solenoid valves, an assembly will need to be constructed that will feed water through one end of the rinse jumper and verify water exiting through the three well ends of the jumper as the solenoids are activated.

To test the rinse water supply solenoid valves on the rinsing jumper, the jumper electrical cord is plugged into the rinse connector in the unloading room. An operator verifies operation of the solenoid valves at the appropriate time.

From the LR-56 cask, an operator sets the cask to the rinsing cycle and initiates the cycle. From the 204-AR unloading room control panel, an operator depresses the "Start" rinse button and verifies that the "Rinsing Authorized" light turns on. When the "Rinsing Authorized" light turns on, the operator in the unloading room should verify that the water supply solenoid valve opens. Each of the well supply valves are then tested by cycling through the valve switches on the 204AR control panel. Pump P1-B is also tested to ensure that it is operable while the cask is in the rinse cycle.

When the cask volume reaches 1 cubic meter of rinse water, the rinse cycle turns off and the rinse permissive signal is turned off to the 204-AR controls. When the cycle ends, the rinse supply water will automatically turn off, stopping pump P1-B and closing all rinse solenoid valves. These interlocks are tested by pumping water into the cask (outside of 204-AR) while the cask is in the rinse cycle. When the volume in the cask reaches 1 cubic meter, the pump will be verified to stop and the rinse valves will be verified to close. Water will continue to be pumped into the 
cask until the cask reaches 2 cubic meters, upon which the emergency stop in the LR-56 will be activated.

One final test of the interlocks will be performed by resetting the LR- 56 controls to the external/indoors unloading mode and verifying that the pump again becomes available.

3.5 Test of Variable Speed Drive (VSD) on Pump P1-B and of Pressure Reducing Valve (PRV) on Raw Water Supply Line

Preliminary - The VSD controls are located on the 204-AR control panel board but are not linked to the LR-56 controls (Section 3.5 may be performed at any time, independent of the other Sections). Testing the VSD requires that water be pumped out of the catch tank and into tank farms. A companion procedure will need to be worked in parallel with this Section. The water will need to be chemically treated, therefore, verification will need to be made that chemicals are available in tanks TK-2 and TK-3 at 204-AR. The administrative lock will need to be removed from pump P1-B prior to testing Section 3.5. If the electrical power leads to the pump motor were lifted earlier in the test, they will need to be restored for this Section.

This test will simulate the pumping of waste from the LR-56 and will also simulate the pumping of rinse water to the rinse heads of the LR-56. The purpose of the test described in this Section is to develop the ideal settings for the VSD control pad for waste pumping and the ideal settings for the VSD control pad and the PRV for rinsing operations.

Using pump P1-B to pump raw water to the catch tank in 204-AR will simulate the LR-56 rinsing operation. The pressure of the water coming out of the pump is essential to the operation of the rinse heads. The PRV and VSD will both be operated at different settings, both to ensure that the PRV and VSD are functioning correctly, and to determine the ideal settings for rinsing operations. It is expected that this simulation will differ from the real operation because the water will be flowing through different pipes and nozzles. The OTP will refine the settings at a later date.

The LR-56 waste pumping operation will be simulated by using pump P1-B to pump the water from the catch tank (put there by the rinsing test) and into tank farms. Prior to pumping, the water will be chemically treated. The flow rate of water being pumped is essential to the unloading operation. The flow rate needs to be slow enough to control the operation. The VSD will be operated at different settings, both to ensure that the VSD is functioning as planned, and to determine the ideal VSD settings for waste unloading. As with rinsing operations, the OTP will refine the settings later.

\subsection{TEST SPECIFICATIONS}

In this Section, the test requirements and test actions required to satisfy the purpose of the test are presented. The criteria identified in each Section of this specification will be confirmed by the ATP test. The documentation of successful completion of each criterion will be provided by the ATP, and in the following test report. Test specifications are provided for each of the five tests outlined in Section 3.0. 


\subsection{Power Connection to the LR-56 Cask - Test Specifications}

The tests to be performed when supplying the LR-56 with power will establish the following:

- Verify that the power cord connection in the unloading room fits the socket on the LR-56.

- Verify that all lights on the LR-56 control panel are lit when the "Light Test" button is pushed.

- Verify that temperature sensors, level detectors, inter-seal pressure detectors and valve position indicators are functioning.

- Verify that the LR-56 backup battery is being charged.

4.2 Fit of Waste Transfer, Vent, and Rinse Fabricated Jumpers - Test Specifications

The tests to be performed on the fabricated jumpers are to verify the following:

- Verify that the rinse jumper fits onto the three rinse valves on the LR-56 cask (in each well), and that a tight seal is obtained.

- Verify that the vent jumper fits onto the vent valve on the LR-56 cask, and that a tight seal is obtained.

- Verify that the waste unloading jumper fits onto the zenith connector on the LR-56 cask, and that a tight seal is obtained.

- Verify that the rinse jumper fits onto the rinse hose in the unloading room, and that a tight seal is obtained.

- Verify that the vent jumper fits onto the vent hose in the unloading room, and that a tight seal is obtained.

- Verify that the waste unloading jumper fits onto the waste unloading hose in the unloading room, and that a tight seal is obtained.

4.3 Control Connection to the LR-56 and 204-AR Controls and Unloading Cycle Interlocks Test Specifications

The tests to be performed to ensure that the LR-56 system and the 204-AR controls are interfacing properly, and that the pump interlock is functioning are:

- Verify that the control cord connection in the unloading room fits the control socket (J3) on the LR-56.

- Verify that the "Power On" light on the 204-AR control panel board lights up when the LR-56 Power Switch (on the 204-AR panel board) is turned on.

- Verify that the "LR-56 connected" light on the 204-AR control panel board lights up when the LR-56 Power Switch (on the 204-AR panel board) is turned on. 
- Verify that the "LR-56 connected" light on the 204-AR control panel board turns off under an emergency shutdown condition. The emergency shutdown condition to be tested is the pushing of the manual emergency shutdown switches (on the LR-56 trailer). The switches to be tested are: 1) control station front panel switch, 2) crane station general switch, 3) crane station local switch, and 4) external switch placed on the enclosure junction box on the left hand side of the trailer.

NOTE - the other emergency shutdown condition occurs when the rinsing water reaches 2 cubic meters. This shutdown condition will be tested in Section 4.4.

- Verify that the pump P1-B interlock is disabling the pump. Push the P1-B start button on the 204-AR control panel board and verify that the pump red (on) light remains off and that the green (off) light remains on. For authorization basis purposes, the leads on the pump motor itself will need to be disconnected to ensure that administrative control (AC) 5.20 remains effective.

- Verify that the "Transfer Authorized" light comes on when the "Request to Transfer" button is depressed.

- Verify that the pump P1-B interlock is now enabling the pump to turn on. Press the pump P1-B start button on the 204-AR control panel board and verify that the pump red (on) light turns on and that the green (off) light turns off.

- Verify that the pump P1-B "Stop" button will stop the pump while the LR-56 is in unloading mode.

\subsection{Rinse Water Supply Valves and Rinse Cycle Interlocks - Test Specifications}

The tests to be performed on the rinse solenoid valves and on the rinse cycle interlocks are to establish the following:

- Verify that the rinse control cable in the unloading room properly connects to the socket connection on the rinse jumper.

- Verify that "Rinsing Authorized" light on the 204-AR control panel board turns on when the rinse "Start" button is depressed.

- Verify that the rinse solenoid valve RWSV-1 opens when the rinse "Start" button is depressed.

- Verify that the rinse solenoid valve RWSV-W\#9 opens when the switch "Rinse Water Solenoid Valve - Well \#9 (RWSV-W\#9) is turned to "Open".

- Verify that the rinse solenoid valve RWSV-W\#10 opens when the switch "Rinse Water Solenoid Valve - Well \#9 (RWSV-W\#10) is turned to "Open".

- Verify that the rinse solenoid valve RWSV-W\#11 opens when the switch "Rinse Water Solenoid Valve - Well \#9 (RWSV-W\#11) is turned to "Open". 
- Verify that the pump P1-B interlock is now enabling the pump to turn on. Press the pump P1-B start button on the 204-AR control panel board and verify that the pump red (on) light turns on and that the green (off) light turns off.

- Verify that all solenoid rinse valves close when the level of the cask reaches between 0.95 and 1.05 cubic meters. If the valves close at a different level, record the level.

- Verify that the pump P1-B interlock is disabling the pump at the same cask volume that the rinse solenoid valves shut. Verify that the pump on/off indicating lights automatically change state.

- Verify that the "LR-56 connected" light on the 204-AR control panel board turns off when the level of the cask reaches between 1.95 and 2.05 cubic meters. If the light turns off at a different level, record the level.

- Verify that the pump P1-B interlock enables the pump to turn on when the "Request to Transfer" button is depressed.

4.5 Variable Speed Drive (VSD) on Pump P1-B and of Pressure Reducing Valve (PRV) on Raw Water Supply Line - Test Specifications

The tests to be performed on the VSD and on the PRV are to establish the following:

\section{Rinsing Operations Simulation:}

- Verify that the VSD is capable of controlling the pressure of rinse water coming out of pump P1-B during the rinsing operation. If the VSD is capable of controlling pressure, determine the ideal VSD setting to maintain a pump output pressure of $60-65$ psi out of the pump using a set supply water pressure (via the VSD) of $60 \mathrm{psi}$. Determine another ideal VSD setting to maintain a pump output pressure of $85-90$ psi out of the pump using a set supply water pressure (via the VSD) of $60 \mathrm{psi}$.

- Verify that the PRV is capable of controlling the pressure of rinse water coming out of pump P1-B during the rinsing operation. Record the pump output pressure of rinse water over a range of PRV settings of $40,60,80$, and 100 psi water supply pressure (using the ideal VSD setting already determined for $85-90$ psi pump output pressure).

\section{Waste Unloading Operations Simulation:}

- Verify that the VSD is capable of controlling the flow rate of waste unloaded from the LR-56. If the VSD is capable of controlling flow rate, determine the ideal VSD setting to maintain a waste flow rate of $20-25$ gallons/minute.

\subsection{ACCEPTANCE TEST PROCEDURE}

The ATP will be written in the same format as onsite operating procedures per HNF-IP-0731. Changes to the ATP will be controlled per the procedure change authorization process as directed by HNF-IP-0842, Volume 1, Section 2.11. The ATP steps will be written to ensure that the objectives specified in this test plan and test specification are met. 
The ATP will be written to test the system and components of the LR-56/204-AR interface as described in Sections 1.0 and 2.0 of this test plan. The ATP will follow the test logic described in Section 3.0 of this test plan. The criteria to be evaluated by the ATP are those specified in Section 4.0 of this test plan.

Other considerations and details that will be developed in the ATP, and not in this test plan are listed below:

- Special equipment

- Safety considerations

- Quality assurance requirements

- Testing personnel requirements and interface of organizations

- Measurement and test equipment calibration requirements

- Troubleshooting and corrective maintenance

- Test program release points

- Requirements for the use of standard PHMC/industry test procedures

When testing the criteria outlined in Section 4.0, a failure may be identified. Such a failure is referred to as a test exception. Test exceptions will be recorded in an exception record, which will be in the ATP. The action necessary to resolve the test exception will also be recorded in the exception record. Upon completion of the action, a retest will be performed. Through the ATP process, problems in the LR-56/204-AR interface will be identified and resolved. An assigned test director will conduct the ATP.

Completion of the ATP and resolution of all test exceptions will be documented in a released acceptance test report (ATR). 